\title{
Wireless Power Transfer Using Class E Inverter with Saturable DC-Feed Inductor
}

\author{
Samer Aldhaher, Patrick C. K. Luk Senior Member, IEEE, Akram Bati \\ School of Engineering, Cranfield University, Bedford, UK \\ p.c.k.luk@cranfield.ac.uk
}

\begin{abstract}
Resonant converters used as coil drivers in inductive links generally operate efficiently at optimum switching conditions for constant load values and ranges. Changes in load and range can shift the operation of the coil driver to a nonoptimum switching state which results in higher switching losses and reduced output power levels. This paper presents a method to adapt to variations in range for a Class $E$ inverter used as a coil driver in a wireless power transfer (WPT) system based on inductive coupling. It is shown that by controlling the duty cycle of the inverter's switch and the value of its DCfeed inductance, the Class $\mathrm{E}$ inverter can be tuned to operate at optimum switching conditions as the distance between the coils of the WPT system changes. Mathematical analysis is presented based on a linear piecewise state-space representation of the inverter and the inductive link. Extensive experimental results are presented to verify the performed analysis and validity of the proposed tuning procedure.
\end{abstract}

Index Terms-Inductive power transmission, Coupling circuits, Resonant inverters, Tunable circuits and devices

\section{INTRODUCTION}

The weak coupling of the coils in an inductive link requires a strong magnetic field to be created to deliver high power levels at large ranges. To achieve this, it requires the use of coil drivers that can generate large currents at frequencies often in the kilohertz and megahertz ranges. The Class $\mathrm{E}$ inverter is a suitable type of DC/AC inverters to meet such a requirement. Invented by the Sokals [1] in 1975, it has been studied extensively and its analysis is well documented in literature [2]-[10]. The Class E inverter is simple to construct, and consists of a single switching element and has a large power handling capability compared to other inverters. It can achieve a theoretical $100 \%$ power efficiency by zerovoltage switching (ZVS) and zero-voltage derivative switching (ZVDS). It is considered as a resonant converter and operates at optimum switching conditions for a fixed value of load and switching frequency. Due to this operating constraint, the use of the Class E inverter as the coil driver in an inductive link means that the wireless power transfer (WPT) system can only operate efficiently for fixed values of load, range and resonant frequency. As a result, novel WPT applications where mobility and dynamic range are required, cannot benefit from the features of the Class E inverter.

The effect of displacement and misalignment of the coils in a WPT system on the performance of Class E inverters are investigated in [11], [12]. It is shown that the displacement of the coils from their optimum position shifts the operation of the Class E inverter to a non-optimum switching condition. As a result, the overall efficiency of the WPT system is degraded and the power delivered to the load is reduced. In addition, large voltages and current spikes can develop in the Class E inverter and may result in permanent damage to the inverter's switching element. Therefore, the Class E inverter will have to be tuned to operate at optimum switching conditions as the displacements in the coils occur. A tuning method has been presented in [12] to allow the Class E inverter to operate optimally by replacing a capacitor and adjusting the switching frequency. This tuning method may not be a practical solution since the inverter has to be powered off before physical replacements and adjustments can be then performed. In [13], adaptive frequency tuning is used at the primary coil driver and an adaptive impedance matching circuit is included at the secondary coil side. The received power is regulated as the range of the coils changes. Although this solution allows for maximum power efficiency to be achieved over a certain coil separation range, it requires complex circuitry and powerful signal processing microcontrollers and does not necessary allow the coil driver to operate at its optimum conditions. In this paper, we extend on our previous work presented in [11] in order to achieve optimum switching conditions of the coil driver by using duty cycle control and saturable reactors.

This paper is organised as follows. Section II provides a brief review on the operation of inductive links. Section III analyses the Class E inverter including the inductive link using a piecewise linear state-space representation. Section IV presents the tuning method of the Class $\mathrm{E}$ inverter and discusses how the values of the duty cycle of the switching signal and DC-feed inductance are calculated to achieve optimum switching conditions. Section $\mathrm{V}$ presents extensive experimental results to verify the analysis of the Class E inverter and to confirm the successful operation of the tuning method. Finally, Section VII includes the conclusion and future work.

\section{Resonant Inductive Links Review}

This section provides a brief review of inductive links, further details can be found in [12], [14]-[23]. An inductive link consists of a primary coil driven by a power current signal at a certain frequency and a secondary coil tuned to that frequency. The secondary coil, to which the load is connected to, can be tuned by using an external capacitor. The secondary coil can also be designed with a self-resonant frequency that is equal to the frequency of the power current signal of the primary coil. Both coils are separated by a certain 


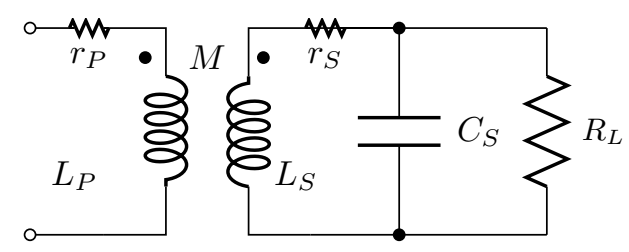

Fig. 1. Resonant coupled coils circuit representation.

distance, may or may not be aligned with each other and may be designed with different dimensions. A dimensionless parameter, referred to as the coupling coefficient $k$, is often used in inductive links to describe the amount of magnetic flux linkage between the two coils as follows

$$
k \equiv \frac{M}{\sqrt{L_{P} L_{S}}}
$$

where $L_{P}$ and $L_{S}$ are the self inductances of the primary and secondary coils respectively and $M$ is the mutual inductance of the two coils. Fig. 1 shows the equivalent circuit of an inductive link. Capacitor $C_{S}$ is connected in parallel with the secondary coil to create resonance. Resistances $r_{P}$ and $r_{S}$ are the equivalent series resistances (ESR) of the primary and secondary coils respectively. The resonant frequency of the secondary coil can be calculated and is given by [14]

$$
f=\frac{1}{2 \pi} \sqrt{\frac{1}{L_{S} C_{S}}-\frac{1}{C_{S}^{2} R_{L}^{2}}} .
$$

\section{ANALYSIS}

The circuit of the Class E inverter along with an inductive link and their equivalent circuit are shown in Fig. 2. The MOSFET drain channel is represented by resistances $r_{\mathrm{ON}}$ and $r_{\mathrm{OFF}}$ for the $\mathrm{ON}$ and OFF intervals respectively. The equivalent circuit is a piecewise linear system an can be described by the following general state-space representation for each $\mathrm{ON}$ and OFF intervals

$$
\dot{X}(\omega t)=A X(\omega t)+B u(\omega t)
$$

where $X=\left[x_{1}, x_{2}, x_{3}, x_{4}, x_{5}, x_{6}\right]^{T}$ is the state vector. The state variables $x_{1}, x_{2}, x_{3}$ represent the voltage across the shunt capacitor $C_{1}$, the voltage across the series capacitor $C_{2}$ and the voltage across the parallel capacitor $C_{S}$ for both $\mathrm{ON}$ and OFF intervals respectively. The states $x_{4}, x_{5}, x_{6}$ represent the current of the DC-feed inductance $L_{f}$, the current of the primary coil $L_{p}$ and the current of the secondary coil $L_{s}$ for both ON and OFF intervals respectively. Resistance $r_{f}$ represents the ESR of the DC-feed inductor. The input vector $u$ is equal to the unit step function. The ON interval's domain is defined as $0 \leq \omega t \leq 2 \pi D$, whereas the domain for the OFF interval is defined as $0 \leq \omega t \leq 2 \pi(1-D)$. Using KVL and
$\mathrm{KCL}$, the following equations can be obtained

$$
\begin{gathered}
V=x_{4} r_{f}+\dot{x}_{4} L_{f}+x_{1} \\
x_{5}=C_{2} \dot{x}_{2} \\
x_{6}=\dot{x}_{3} C_{S}+\frac{x_{3}}{R_{L}} \\
V=x_{4} r_{f}+\dot{x}_{4} L_{f}+x_{1} \\
x_{4}=\frac{x_{1}}{r_{\mathrm{ON} / \mathrm{OFF}}}+\dot{x}_{1} C_{1}+x_{5} \\
x_{1}=x_{2}+x_{5} r_{p}+\dot{x}_{5} L_{p}-\dot{x}_{6} M \\
\dot{x}_{5} M=\dot{x}_{6} L_{S}+x_{6} r_{s}+x_{3} .
\end{gathered}
$$

Using Equ. 9-10, the derivative states $\dot{x_{5}}$ and $\dot{x_{6}}$ can be written as

$$
\begin{aligned}
& \dot{x_{5}}=\frac{1}{L_{p} L_{s}-M^{2}}\left(x_{1} L_{s}-x_{2} L_{s}-x_{3} M-x_{5} L_{s} r_{p}-x_{6} M r_{s}\right) \\
& \dot{x_{6}}=\frac{1}{L_{p} L_{s}-M^{2}}\left(x_{1} M-x_{2} M-x_{3} L_{p}-x_{5} M r_{p}-x_{6} L_{p} r_{s}\right) .
\end{aligned}
$$

Based on Eqs. 4-7 and Eqs. 11-12, the matrices $A, B, C$ and $D$ for both ON and OFF intervals are given by

$$
A_{\mathrm{ON} / \mathrm{OFF}}=\left[\begin{array}{ccc}
\frac{-1}{r_{\mathrm{ON} / \mathrm{OFF}} C_{1}} & 0 & 0 \\
0 & 0 & 0 \\
0 & 0 & \frac{-1}{R_{L} C_{S}} \\
\frac{-1}{L_{f}} & 0 & 0 \\
\frac{L_{s}}{L_{p} L_{s}-M^{2}} & \frac{-L_{s}}{L_{p} L_{s}-M^{2}} & \frac{-M}{L_{p} L_{s}-M^{2}} \\
\frac{M}{L_{p} L_{s}-M^{2}} & \frac{-M}{L_{p} L_{s}-M^{2}} & \frac{-L_{p}}{L_{p} L_{s}-M^{2}}
\end{array} \ldots\right.
$$

$$
\left.\begin{array}{ccc}
\frac{1}{C_{1}} & \frac{-1}{C_{1}} & 0 \\
0 & \frac{1}{C_{2}} & 0 \\
\cdots & 0 & \frac{1}{C_{S}} \\
\frac{-r_{f}}{L_{f}} & 0 & 0 \\
0 & \frac{-L_{s} r_{p}}{L_{p} L_{s}-M^{2}} & \frac{-M r_{s}}{L_{p} L_{s}-M^{2}} \\
0 & \frac{-M r_{p}}{L_{p} L_{s}-M^{2}} & \frac{-L_{p} r_{s}}{L_{p} L_{s}-M^{2}}
\end{array}\right]
$$

The solution to Eq. 3 for the ON and OFF intervals can be written in the form

$$
\begin{aligned}
x_{\mathrm{ON}}(\omega t) & =e^{A_{\mathrm{ON}} \omega t} x_{\mathrm{ON}}(0)+A_{\mathrm{ON}}^{-1}\left(e^{A_{\mathrm{ON}} \omega t}-\mathbf{I}\right) B \\
x_{\mathrm{OFF}}(\omega t) & =e^{A_{\mathrm{OFF}} \omega t} x_{\mathrm{OFF}}(0)+A_{\mathrm{OFF}}^{-1}\left(e^{A_{\mathrm{OFF}} \omega t}-\mathbf{I}\right) B
\end{aligned}
$$

where $x_{\mathrm{ON}}(0)$ and $x_{\mathrm{OFF}}(0)$ are the initial conditions for the $\mathrm{ON}$ and OFF states respectively and $\mathbf{I}$ is a $6 \times 6$ identity 


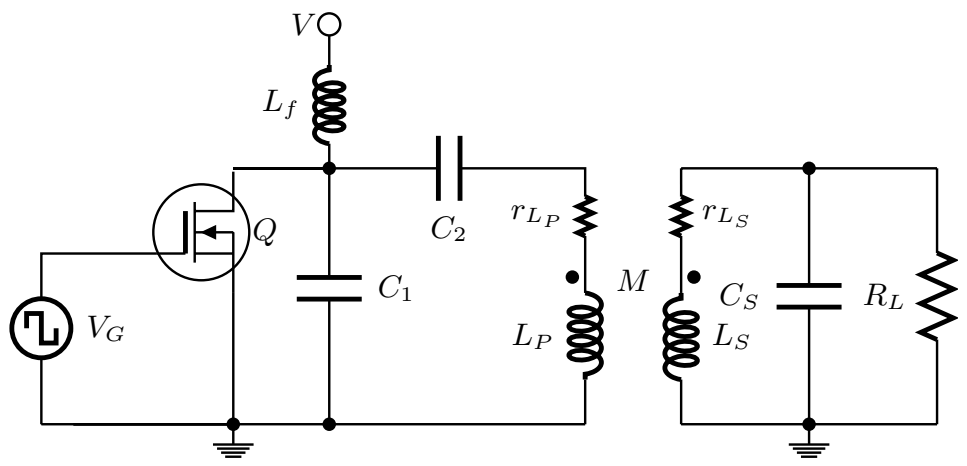

(a) Class E inverter with an inductive link

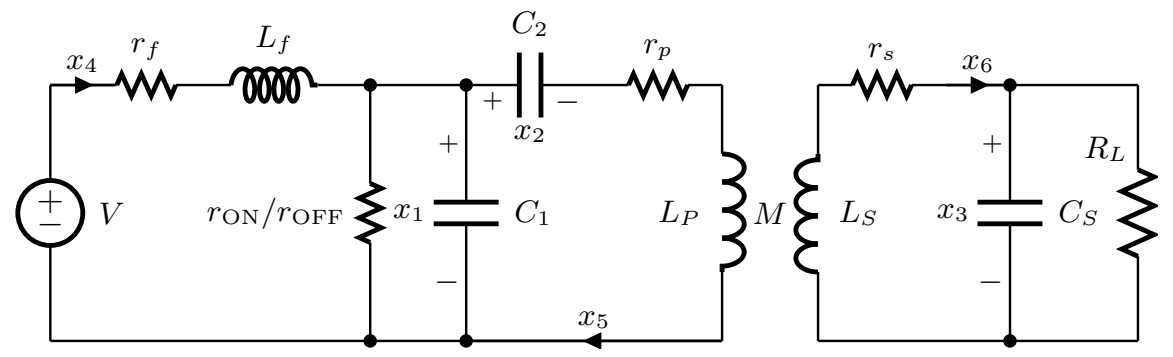

(b) Equivalent circuit

Fig. 2. Class E inverter and the inductive link for both ON and OFF intervals

matrix. The initial conditions are determined by applying the continuity conditions of the voltages across $C_{1}, C_{2}$ and $C_{S}$ and the currents of $L_{f}, L_{p}$ and $L_{s}$ when the circuit transitions from the ON state to the OFF state, hence the following equations are obtained

$$
\begin{gathered}
x_{\mathrm{ON}}(0)=\left.x_{\mathrm{OFF}}(\omega t)\right|_{\omega t=2 \pi(1-D)} \\
x_{\mathrm{OFF}}(0)=\left.x_{\mathrm{ON}}(\omega t)\right|_{\omega t=2 \pi D} .
\end{gathered}
$$

By evaluating the above equations, the initial conditions are equal to the following

$$
\begin{aligned}
{\left[\begin{array}{c}
x_{\mathrm{ON}}(0) \\
x_{\mathrm{OFF}}(0)
\end{array}\right]=\left[\begin{array}{cc}
-e^{A_{\mathrm{ON}} 2 \pi D} & \mathbf{I} \\
\mathbf{I} & -e^{A_{\mathrm{OFF}} 2 \pi(1-D)}
\end{array}\right]^{-1} } \\
\\
{\left[\begin{array}{c}
A_{\mathrm{ON}}^{-1}\left(e^{A_{\mathrm{ON}} 2 \pi D}-\mathbf{I}\right) \\
\left.A_{\mathrm{OFF}}^{-1}\left(e^{A_{\mathrm{OFF}} 2 \pi(1-D}\right)-\mathbf{I}\right)
\end{array}\right] B . }
\end{aligned}
$$

For optimal switching conditions, i.e. ZVS and ZVDS, the following states should be equal to the following

$$
\begin{aligned}
& x_{\mathrm{ON} 1}(0)=0 \\
& x_{\mathrm{ON} 3}(0)-x_{\mathrm{ON} 4}(0)=0 .
\end{aligned}
$$

The average DC current $I$ to the inverter is equal to the average value of the DC-feed inductor's current

$$
I=\frac{1}{2 \pi}\left(\int_{0}^{2 \pi D} x_{\mathrm{ON} 4}(\omega t) d \omega t+\int_{0}^{2 \pi(1-D)} x_{\mathrm{OFF} 4}(\omega t) d \omega t\right) .
$$

\section{OptimisATION AND TUNING}

The variation of the coupling coefficient between the primary and the secondary coils of the inductive link, due to a change of the distance between the coils, will alter the operation of the Class E inverter from its optimal switching conditions. It is therefore necessary to recalculate the values of its components as the coupling coefficient changes to ensure optimum switching operation.

Due to practical considerations, it is not desirable to replace the components of the Class $\mathrm{E}$ inverter for every change that occurs in the coupling coefficient. Achieving the two optimum switching conditions, ZVS and ZVDS, implies that at least two operating parameters and/or component values should be controlled. The simplest parameters that can be controlled are the duty cycle of the MOSFET gate switching signal and its frequency. However, controlling the frequency may not be a viable solution since that might reduce the power transfer efficiency of the inductive link. As a result, the value of either $L_{f}, C_{1}$ or $C_{2}$ should be controlled in addition to the duty cycle of the MOSFET gate drive signal. We choose to control the value of $L_{f}$ since it is practically possible to implement by using magnetic amplifiers or saturable reactors. Using Eqs. 19, 20 and 21, the values of the duty cycle and $L_{f}$ can be numerically solved. Fig. 3 shows solutions of the duty cycle and $L_{f}$ as the coupling coefficient varies from 0.2 to 0.45 for a WPT system. The complete specifications of the WPT system, including the Class E inverter and the inductive link, are summarised in Table I.

\section{HARDWARE SETUP}

To verify the performed analysis and the proposed tuning method, a WPT system consisting of a Class E inverter and an inductive link is implemented as shown in Fig. 4. The complete specifications are summarised in Table I. A function generator is connected to the MOSFET driver to vary the duty cycle of the MOSFET's switching signal. The control 


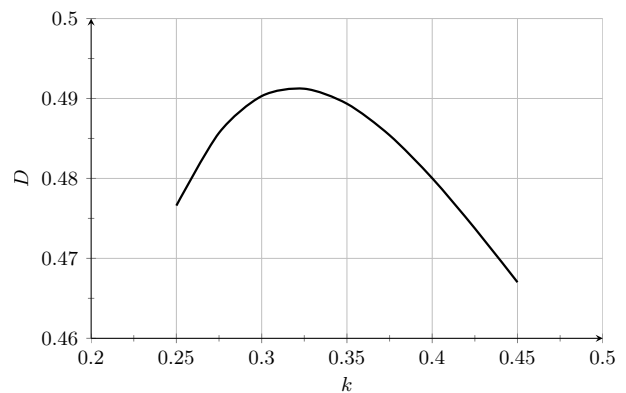

(a) duty cycle

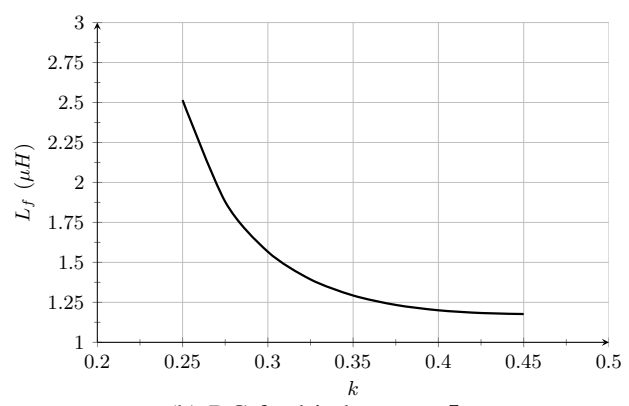

(b) DC-feed inductance $L_{f}$

Fig. 3. Solutions of the duty cycle and the DC-feed inductance.

of the DC-feed inductance is achieved by using a saturable reactor. The saturable reactor consists of two windings, a primary winding which represents the DC-feed inductance to be controlled and a control winding which is connected to a variable DC current source. Both windings are wound on a 3C90 ferrite core from Ferroxcube. Ferrite cores generally have lower eddy current and hysteresis than other magnetic cores, such as iron powder. By varying the DC current source, the amount of magnetic flux that is injected into the magnetic core via the control windings is altered, which in turn alters the inductance of the primary windings that represent the DC-feed inductor. Detailed description about the operation of saturable reactors and their applications can be found in [24]. The DCfeed inductance is at a maximum when the control DC current is zero and decreases as the control DC current is increased. Two saturable reactors are used with their primary windings connected in phase and their control windings connected in antiphase manner to cancel the induced voltage in the control windings.

The ESR of the saturable DC-feed inductors is not constant, but varies according to frequency, temperature, the DC bias operating point and the intensity of the $\mathrm{AC}$ flux due to the current in the primary windings. The total losses in an inductor increase as it saturates since its inductance is lower and its current increases. This leads to higher ohmic losses in the windings and higher hysteresis losses in the core. However, a constant ESR value had been assumed to simplify the analysis and to obtain the solutions of the duty cycle and the DC-feed inductance in Fig. 3. An ESR value of $0.3 \Omega$ was obtained during initial measurements. In this setup, the temperature of the inductors is monitored to provide an indication of how significant the losses of the saturable DC-feed inductors are.

The primary coil of the inductive link consists of two layers

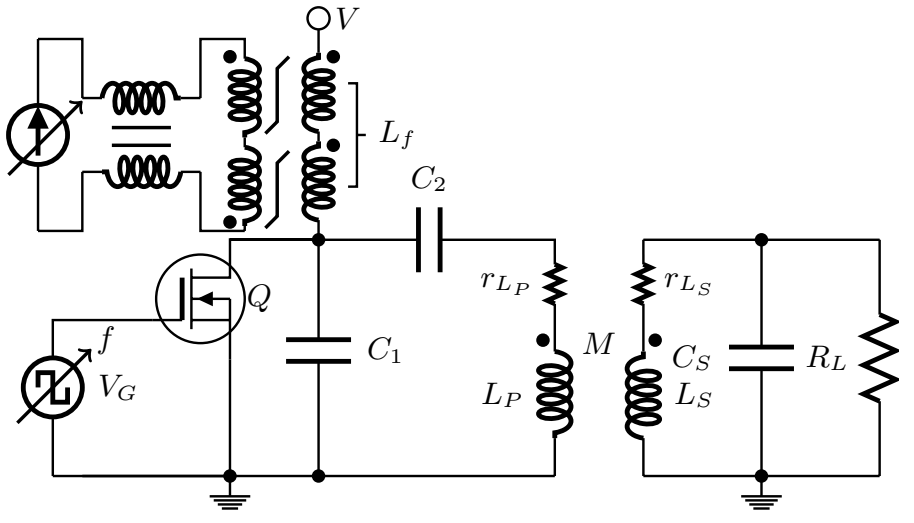

Fig. 4. The implemented circuit of the Class E inverter and the inductive link.

TABLE I

VALUES AND RANGES OF SEVERAL PARAMETERS OF THE ClASS E INVERTER AND THE INDUCTIVE LINK MEASURED AT $800 \mathrm{KHZ}$

\begin{tabular}{|c|c|c|}
\hline \multirow{9}{*}{ 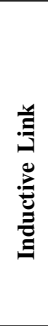 } & Component/Parameter & Value \\
\hline & $L_{P} / r_{P}$ & $5.76 \mu \mathrm{H} / 0.17 \Omega$ \\
\hline & $L_{S} / r_{S}$ & $5 \mu \mathrm{H} / 0.28 \Omega$ \\
\hline & $C_{S}$ & $5.92 \mathrm{nF}$ \\
\hline & Resonant Frequency $f_{o}$ & $750 \mathrm{kHz}$ \\
\hline & $R_{L}$ & $47 \Omega$ \\
\hline & Mutual Inductance $(M)$ Range & $1.37-2.23 \mu \mathrm{H}$ \\
\hline & Coupling Coefficient $(k)$ Range & $0.25-0.45$ \\
\hline & Coils Separation Dist. Range & $0.5-2.5 \mathrm{~cm}$ \\
\hline \multirow{9}{*}{ 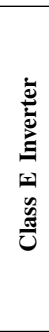 } & Component/Parameter & Value \\
\hline & MOSFET & STP40NF10 \\
\hline & Gate Driver & TC1412 \\
\hline & $r_{\mathrm{ON}} / r_{\mathrm{OFF}}$ & $0.15 \Omega / \infty$ \\
\hline & Input Voltage & $8 \mathrm{~V}$ \\
\hline & $C_{1}$ & $22 \mathrm{nF}$ \\
\hline & $C_{2}$ & $7.9 \mathrm{nF}$ \\
\hline & Switching Frequency $f_{s}$ & $800 \mathrm{kHz}$ \\
\hline & Duty Cycle Range & $40-50 \%$ \\
\hline \multirow{9}{*}{ 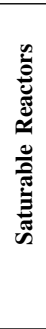 } & Component/Parameter & Value \\
\hline & Core Type & $3 \mathrm{C} 90$ \\
\hline & No. of Cores & 2 \\
\hline & Primary turns per core & 2.5 \\
\hline & Control turns per core & 70 \\
\hline & Control winding's resistance per core & $0.23 \Omega$ \\
\hline & $r_{f}$ & $0.3 \Omega$ \\
\hline & Control Current Range $I$ & $0.00-1.50 \mathrm{~A}$ \\
\hline & $L_{f}$ Range & $3-1 \mu \mathrm{H}$ \\
\hline
\end{tabular}

each having four turns of 18 AWG magnetic wire and a radius of $8 \mathrm{~cm}$. The secondary coil consists of a single layer of four turns of 20 AWG magnet wire with a radius of $7 \mathrm{~cm}$. The mutual inductance was measured using the PSM1700 PsimetriQ phase sensitive multimeter. The coupling coefficient of the coils is calculated using Eq. 1 and is plotted in Fig. 5. A photograph of the complete experimental setup is shown in Fig. 6.

\section{EXPERIMENTAL ReSUlts AND Discussion}

The validation process was performed as follows. The coils were kept at an initial separation distance of $2.5 \mathrm{~cm}$ and were brought closer to each other in steps of $0.25 \mathrm{~cm}$ to a distance 


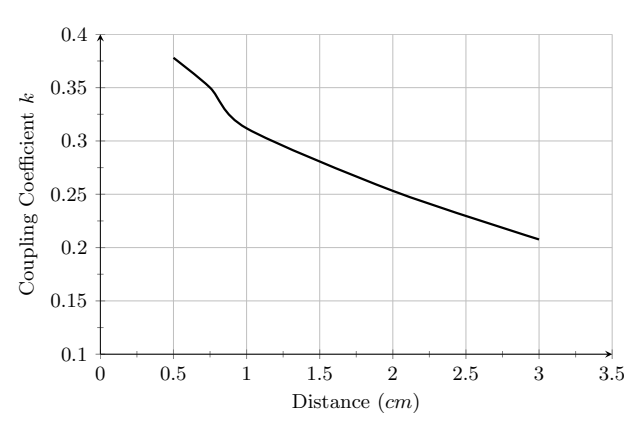

Fig. 5. The calculated coupling coefficient as the coils of the inductive link are displaced while maintaining alignment.

$0.5 \mathrm{~cm}$. The duty cycle and the control current of the saturable reactors were varied according to Fig. 3 to achieve optimum switching conditions over the entire distance range. Fig. 7 shows several measured parameters over the entire separation range of the coils. In Fig. 7a, the measured values of the duty cycle required to achieve optimum switching conditions are compared with the theoretical values shown in Fig. 3. The discrepancies are due to the finite rise and fall times of the MOSFET and the MOSFET driver. Fig. $7 \mathrm{~b}$ shows the values of the DC control current of the saturable reactors. The values of the DC-feed inductance cannot be measured accurately since several factors could affect the inductance such as the amplitude of the input current, the switching frequency and input voltage. The temperature of the saturable reactors was below $50^{\circ} \mathrm{C}$ over the entire distance range which indicates that the losses in the saturable reactors are not significant.

Figs. $7 \mathrm{c}-\mathrm{g}$ show the variation of voltages and currents throughout the inverter over the entire distance range. The input power and the transmitted power are plotted in Fig. $7 \mathrm{~h}$. A peak occurs at a distance of $1.25 \mathrm{~cm}$ corresponding to a coupling coefficient value of 0.3 . The measured overall system efficiency, i.e. DC-to-load, and the measured efficiency of the inductive link are shown in Figs. $7 \mathrm{~h}$ and $7 \mathrm{i}$ respectively. The overall system efficiency covers the losses of the primary windings of the saturable reactors, the switching losses in the Class $\mathrm{E}$ inverter and the losses in the inductive link. The power loss in the control windings of the saturable reactors was not included in the overall system efficiency. It is noted that the power loss in the control windings can be calculated from Fig. $7 \mathrm{~b}$ and its peak is $0.911 \mathrm{~W}$ at a maximum control current of $1.35 \mathrm{~A}$. The efficiency of the inductive link increases as the coils are brought closer to each other since the reflected impedance of the load becomes more significant than that of the ESR of the coils. The overall efficiency increases as the coils are brought closer and remains relatively constant at $80 \%$ for larger coupling coefficient values.

Figs. 8 and 9 show the experimental waveforms of the voltages and currents throughout the Class E inverter and the inductive link respectively. In Fig. 8a and Fig. 9a, the inverter is operating at optimum switching conditions achieving ZVS and ZVDS. The separation distance is $1.25 \mathrm{~cm}$ corresponding to a coupling coefficient of 0.3 , the DC control current is $0.85 \mathrm{~A}$, the duty cycle of the switching signal is $49.5 \%$ and the power delivered to the load is $11.75 \mathrm{~W}$. Theoretical

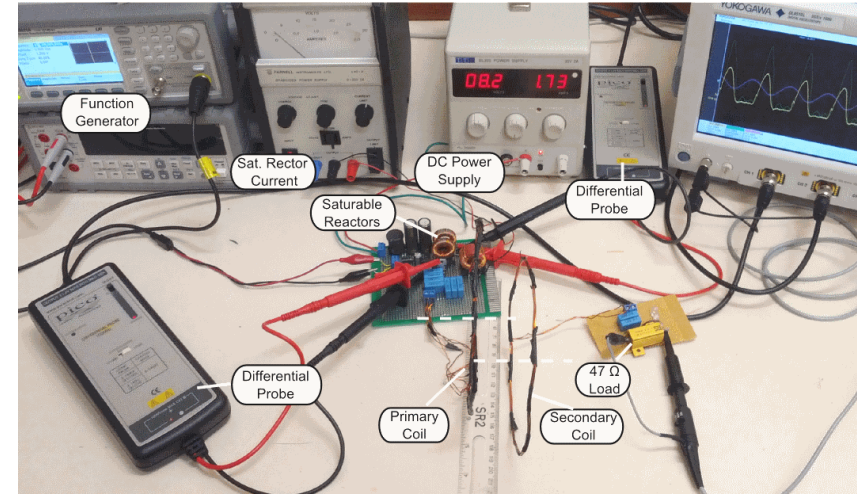

Fig. 6. Photograph of the experimental setup.

waveforms are also plotted and are in good agreement with the experimental waveforms. In Fig. 8b and Fig. 9b, the coils are brought closer to each other to a separation distance of $0.75 \mathrm{~cm}$ corresponding to a coupling coefficient of 0.35 while maintaining the same DC control current and duty cycle. Since the coupling coefficient has now changed, the Class E inverter no longer operates at optimum switching conditions since the MOSFET is being switched ON at a non-zero voltage as can be seen in the figures. The non-optimum switching conditions result in distortion of the voltage and current waveforms. This causes excessive losses in the form of heat and reduces the amount of power that can be delivered over the load which in this case is now $7.70 \mathrm{~W}$. In Fig. 8c and Fig. 9c, the inverter is retuned and is now operating at optimum switching conditions by decreasing the duty cycle of the switching signal to $48.0 \%$ and increasing the DC control current to $1.35 \mathrm{~A}$. Theoretical waveforms are also plotted and are found to match the new experimental waveforms. The power delivered to load has now increased to $8.92 \mathrm{~W}$. Therefore, the proposed tuning method of controlling the duty cycle of the switching frequency and DCfeed inductance has been successfully demonstrated allowing the Class E inverter to operate safely and efficiently over a certain coil displacement range.

\section{CONClusion AND Future Work}

A novel method has been presented to tune Class $\mathrm{E}$ inverters that are used as primary coil drivers in WPT systems based on inductive coupling. By varying the inductance of the DCfeed inductor via a DC current source and the duty cycle of the MOSFET's switching signal, the Class E inverter can operate at optimised switching conditions achieving ZVS and ZVDS as the coupled coils of the inductive link are displaced. This tuning method may be applied to certain WPT applications such as inductive charging for electric vehicles and mobile devices where displacements and misalignments of the coils are likely to occur. Mathematical analysis has been performed to derive the voltage and current relationships of the Class $\mathrm{E}$ inverter and the inductive link using a piecewise linear state-space representation. The equations derived are used to numerically calculate the required duty cycle and the DC-feed inductance for tuning as the coupling coefficient of the inductive link changes. Extensive experimental results 


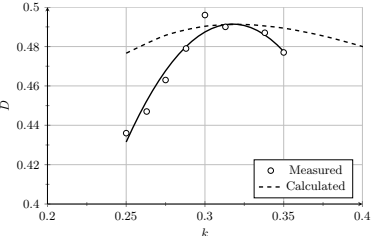

(a) Measured duty cycle.

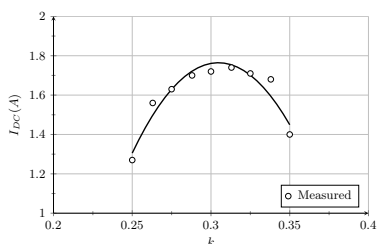

(c) Measured input DC current.

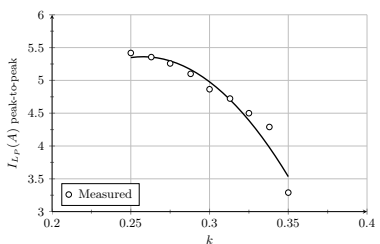

(e) Measured primary coil current.

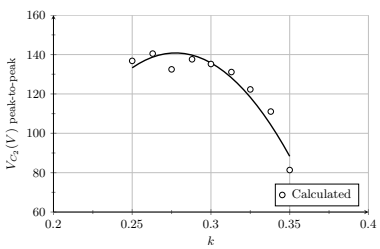

(g) Calculated voltage of $C_{2}$.

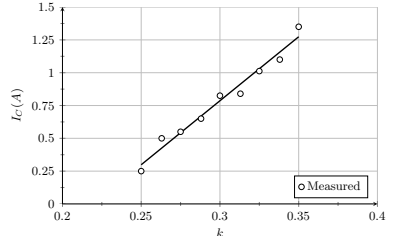

(b) Measured control current.

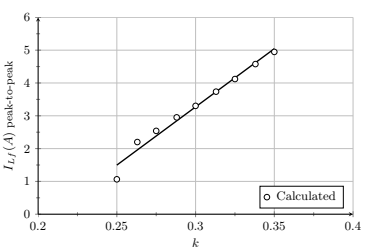

(d) Calculated DC-feed inductor's current.

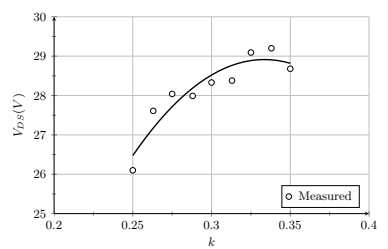

(f) Measured MOSFET peak voltage.

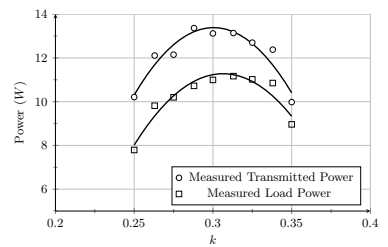

(h) Measured power.

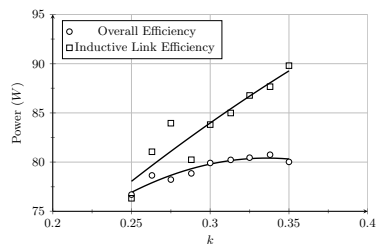

(i) Measured efficiencies

Fig. 7. Measured and calculated parameters, voltages and currents over a certain coupling coefficient range.

are presented which verify the performed analysis and the successful operation of the proposed tuning method.

Since only manual feedback has been used in tuning the current system, future work should include designing controllers to achieve automatic tuning. Moreover, improving the modelling of the Class $\mathrm{E}$ inverter can be further improved by including the saturable reactor instead of a single inductor representation. In addition, investigation into high frequency, efficient rectifiers such as Class E rectifiers could be performed to produce a DC voltage output in the secondary coil circuitry of the inductive link.
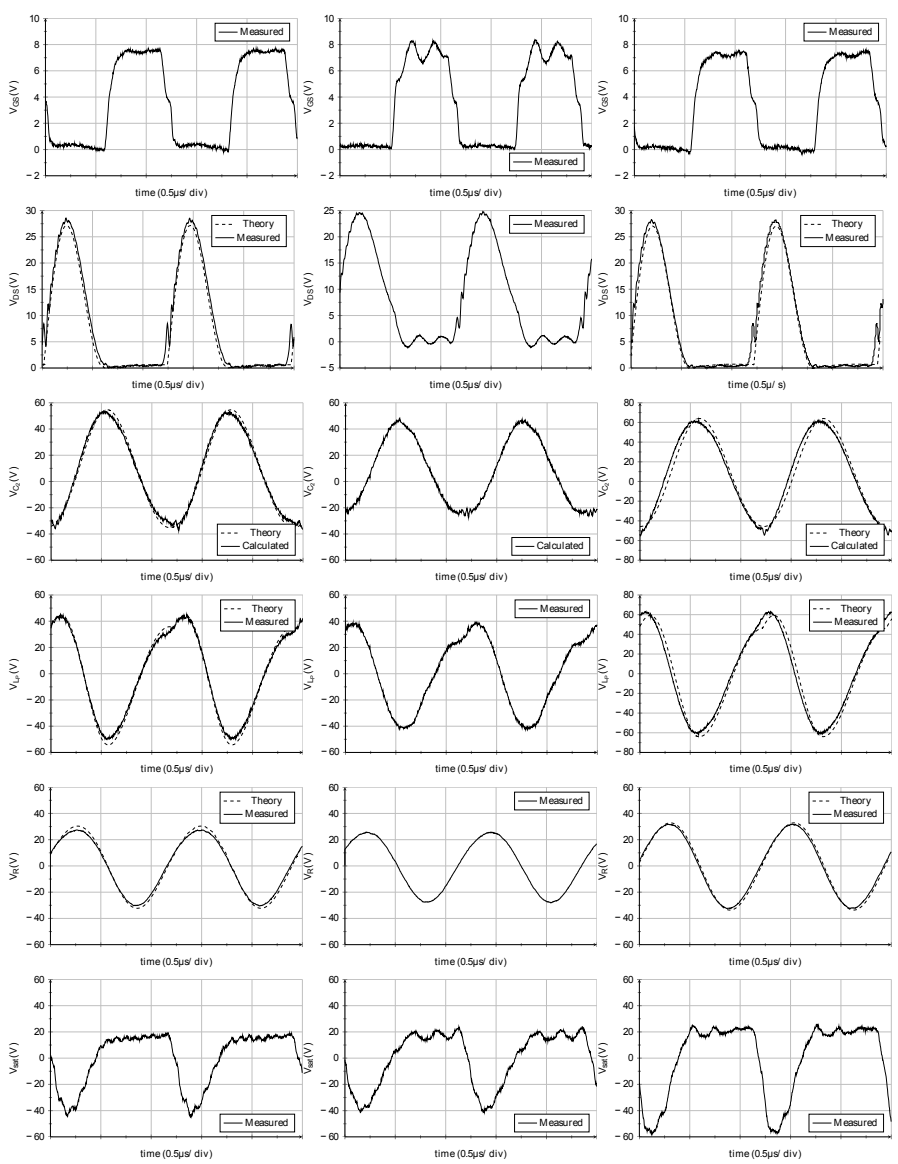

(a) Tuned optimum opera-(b) Untuned non-optimum(c) Retuned optimum option at $k=0.25$.

operation at $k=0.35$. eration at $k=0.35$.

Fig. 8. Voltage waveforms of the implemented WPT system at different coupling coefficients demonstrating the proposed tuning method. The waveforms represent the MOSFET's gate driving signal $V_{G S}$, the MOSFET's drain voltage $V_{D S}$, the voltage across the series capacitor $V_{C_{2}}$, the voltage across the primary coil $V_{L_{P}}$, the output voltage at the load $V_{R}$ and the voltage developed across the control windings of one of the saturable reactors $V_{\text {sat }}$.
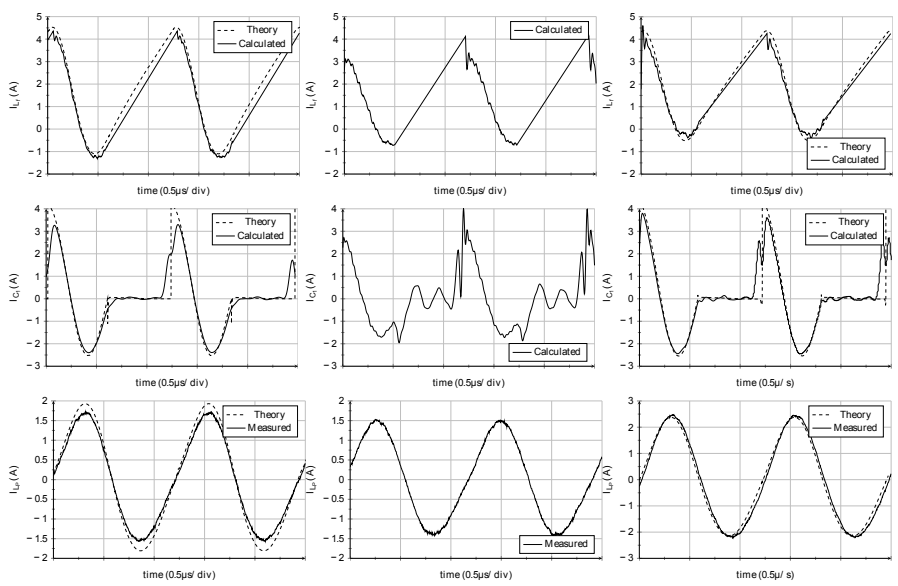

(a) Tuned optimum oper tion at $k=0.25$. operation at $k=0.35$.

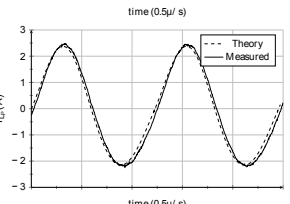

Fig. 9. Current waveforms of the implemented WPT system at different coupling coefficients demonstrating the proposed tuning method. The waveforms represent the DC-feed inductor's current $I_{L_{f}}$, the shunt capacitor's current $I_{C_{1}}$ and the primary coil's current $I_{L_{P}}$. 


\section{REFERENCES}

[1] N. O. Sokal and A. D. Sokal, "Class E-a new class of high-efficiency tuned single-ended switching power amplifiers," IEEE J. Solid-State Circuits, vol. 10, no. 3, pp. 168 - 176, Jun. 1975.

[2] A. Grebennikov and N. O. Sokal, Switchedmode RF Power Amplifiers. Oxford, UK: Newnes, 2007.

[3] M. Kazimierczuk and K. Puczko, "Exact analysis of Class-E tuned power amplifier at any Q and switch duty cycle," IEEE Trans. Circuits Syst., vol. 34, no. 2, pp. 149-159, Feb. 1987.

[4] M. K. Kazimierczuk, RF Power Amplifiers. Chichester, UK: John Wiley \& Sons, 2008.

[5] M. K. Kazimierczuk and D. Czarkowski, Resonant Power Converters, 2nd ed. New Jersey, USA: John Wiley \& Sons, 2011.

[6] M. Kazimierczuk and X. Bui, "Class E DC/DC converters with an inductive impedance inverter," IEEE Trans. Power Electron., vol. 4, no. 1, pp. 124-135, Jan. 1989.

[7] D. Kessler and M. Kazimierczuk, "Power losses and efficiency of ClassE power amplifier at any duty ratio," IEEE Trans. Circuits Syst. I, Reg. Papers, vol. 51, no. 9, pp. 1675-1689, Sep. 2004.

[8] T. Suetsugu and M. Kazimierczuk, "Design procedure of Class-E amplifier for off-nominal operation at 50\% duty ratio," IEEE Trans. Circuits Syst. I, Reg. Papers, vol. 53, pp. 1468-1476, Jul. 2006.

[9] — "Off-nominal operation of Class-E amplifier at any duty ratio," IEEE Trans. Circuits Syst. I, Reg. Papers, vol. 54, no. 6, pp. 1389-1397, Jun. 2007.

[10] _ "Analysis and design of Class-E amplifier with shunt capacitance composed of nonlinear and linear capacitances," IEEE Trans. Circuits Syst. I, Reg. Papers, vol. 51, no. 7, pp. 1261-1268, Jul. 2004.

[11] S. Aldhaher, P. C. K. Luk, and J. F. Whidborne, "Tuning Class inverters applied in inductive links using saturable reactors," IEEE Trans. Power Electron., vol. to be published, 2013.

[12] M. Pinuela, D. C. Yates, S. Lucyszyn, and P. D. Mitcheson, "Maximizing DC-to-load efficiency for inductive power transfer," IEEE Trans. Power Electron., vol. 28, no. 5, pp. 2437 - 2447, May 2013.

[13] A. Sample, B. Waters, S. Wisdom, and J. Smith, "Enabling seamless wireless power delivery in dynamic environments," Proc. IEEE, vol. 101, no. 6, pp. 1343-1358, Apr. 2013.

[14] B. Lenaerts and R. Puers, Inductive Link Design, ser. Analog Circuits and Signal Processing. Springer Netherlands, 2009.

[15] J. P. C. Smeets, T. T. Overboom, J. W. Jansen, and E. A. Lomonova, "Comparison of position-independent contactless energy transfer systems," IEEE Trans. Power Electron., vol. 28, no. 4, pp. 2059-2067, Apr. 2013.

[16] K. Fotopoulou and B. Flynn, "Wireless power transfer in loosely coupled links: Coil misalignment model," IEEE Trans. Magn., vol. 47, no. 2, pp. 416-430, Feb. 2011.

[17] R. Jegadeesan, Y.-X. Guo, and M. Je, "Overcoming coil misalignment using magnetic fields of induced currents in wireless power transmission," in IEEE Int. Microwave Symp. Dig. (MTT),, Jun. 2012, pp. 1-3.

[18] T. P. Duong and J.-W. Lee, "Experimental results of high-efficiency resonant coupling wireless power transfer using a variable coupling method," IEEE Microw. Wireless Compon. Lett., vol. 21, no. 8, pp. 442 - 444, Aug. 2011.

[19] W. Zhong, C. K. Lee, and S. Hui, "General analysis on the use of Tesla's resonators in domino forms for wireless power transfer," IEEE Trans. Ind. Electron., vol. 60, no. 1, pp. 261 - 270, Jan. 2013.

[20] H. Wu, G. Covic, J. Boys, and D. Robertson, "A series-tuned inductivepower-transfer pickup with a controllable AC-voltage output," IEEE Trans. Power Electron., vol. 26, no. 1, pp. 98-109, Jan. 2011.

[21] S.-H. Lee and R. Lorenz, "Development and validation of model for 95\%-efficiency 220 -W wireless power transfer over a 30 -cm air gap," IEEE Trans. Ind. Appl., vol. 47, no. 6, pp. 2495-2504, 2011.

[22] Z. Pantic and S. Lukic, "Wireless power transfer in loosely coupled links: Coil misalignment model," IEEE Trans. Power Electron., vol. 27, no. 11, pp. 4503-4513, Nov. 2012.

[23] K. Schuylenbergh and R. Puers, Automatic link tuning. Springer Netherlands, 2009.
[24] "Magnetic amplifiers: A rising star in naval electronics," Electronics Design and Development Division, Bureau of Ships, U. S. Navy, 1951.

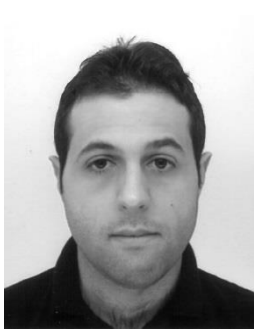

Samer Aldhaher received the B.Sc. degree in electrical engineering from the University of Jordan, Amman, Jordan in 2010. He is currently working towards the Ph.D. degree at Cranfield University, Bedford, UK.

His current research interests include the design of high frequency DC/AC inverters, wireless power transfer applications based on resonant inductive links and switched-mode circuits.

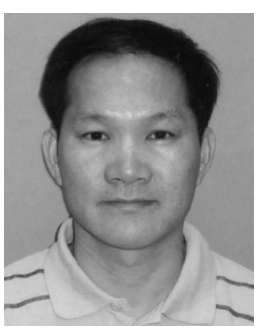

Patrick Chi-Kwong Luk (M'92-SM'08) is a native of Hong Kong. He received the High Diploma with merits (BSc) from Hong Kong Polytechnic University (PolyU), Hong Kong, in 1983, the M.Phil. degree from Sheffield University, U.K., in 1989, and the Ph.D. degree from the University of South Wales, U.K., in 1992, all in electrical engineering.

$\mathrm{He}$ started his career first in industry as an Assistant Engineer at GEC (H.K.) and then Application Engineer at Polytek Engineering Co. (H.K.). In 1986, he began his academic career as a Researcher at PolyU. Since 1988, he had held academic positions at the University of South Wales, U.K., Robert Gordon University, U.K., and University of Hertfordshire, U.K. In 2002, he joined Cranfield University, U.K., where he is currently Chair Professor in Electrical Engineering and Head of the Electric Power and Drives Group, School of Engineering. He is the Chairman of the IEEE UK\&RI Young Professionals and Professional Activities Affinity Groups, and is an Associate Editor for IEEE Transactions in Power Electronics. He has over 140 technical publications in electrical machines and drives. His main current research interests include electrical machines and converters for future transport and renewable energy applications. He has been invited as keynote speaker at international conferences.

A Senior Member of the IEEE, he won the 2011 IET Premium Award in Electric Power Applications.

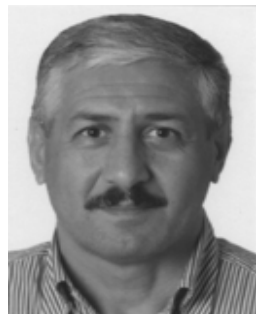

Akram Bati Akram Bati received the BSc in Electrical Engineering from Baghdad University , Iraq in 1980, the MSc and the PhD in Electrical Power Systems from Cranfield Institute of Technology (CIT) in 1985 and 1988 respectively. He started his career first in industry as O\&M Engineer. In 1984 he began his academic research as assistant lecturer in the University of Technology, Baghdad, Iraq and then joined CIT to do his MSc and PhD degrees. Since 1988, he had held academic positions at the University of Technology, Iraq, and Mutah University, Jordan, and Kwazulu Natal University, Durban, South Africa. In 2011 he joined Cranfield University as academic visitor and then in 2013 as a member of staff in the group of Electric Power and Drives. He has over 30 technical publications in the area of Power Systems and he is a member of IEEE PES.

He served as TCP of many IEEE conferences on smart grids and Power Engineering and he is a regular peer reviewer for IEEE Transactions and EPSRC proposals. His main current research is on smart grids stability and optimized load flow. 